\title{
Bioinformatic analysis of beta carbonic anhydrase sequences from protozoans and metazoans
}

\author{
Reza Zolfaghari Emameh ${ }^{1,2^{*}}$, Harlan Barker ${ }^{1,2}$, Martti E E Tolvanen ${ }^{2,3}$, Csaba Ortutay $^{2}$ and Seppo Parkkila ${ }^{1,2,4}$
}

\begin{abstract}
Background: Despite the high prevalence of parasitic infections, and their impact on global health and economy, the number of drugs available to treat them is extremely limited. As a result, the potential consequences of large-scale resistance to any existing drugs are a major concern. A number of recent investigations have focused on the effects of potential chemical inhibitors on bacterial and fungal carbonic anhydrases. Among the five classes of carbonic anhydrases (alpha, beta, gamma, delta and zeta), beta carbonic anhydrases have been reported in most species of bacteria, yeasts, algae, plants, and particular invertebrates (nematodes and insects). To date, there has been a lack of knowledge on the expression and molecular structure of beta carbonic anhydrases in metazoan (nematodes and arthropods) and protozoan species.
\end{abstract}

Methods: Here, the identification of novel beta carbonic anhydrases was based on the presence of the highly-conserved amino acid sequence patterns of the active site. A phylogenetic tree was constructed based on codon-aligned DNA sequences. Subcellular localization prediction for each identified invertebrate beta carbonic anhydrase was performed using the TargetP webserver.

Results: We verified a total of 75 beta carbonic anhydrase sequences in metazoan and protozoan species by proteome-wide searches and multiple sequence alignment. Of these, 52 were novel, and contained highly conserved amino acid residues, which are inferred to form the active site in beta carbonic anhydrases. Mitochondrial targeting peptide analysis revealed that 31 enzymes are predicted with mitochondrial localization; one was predicted to be a secretory enzyme, and the other 43 were predicted to have other undefined cellular localizations.

Conclusions: These investigations identified 75 beta carbonic anhydrases in metazoan and protozoan species, and among them there were 52 novel sequences that were not previously annotated as beta carbonic anhydrases. Our results will not only change the current information in proteomics and genomics databases, but will also suggest novel targets for drugs against parasites.

Keywords: Beta carbonic anhydrase, Inhibitor, Metazoa, Mitochondrial targeting peptide, Multiple sequence alignment, Protozoa

\section{Background}

Carbonic anhydrases (CAs) are ubiquitous metalloenzymes. They are encoded by five evolutionary divergent gene families and the corresponding enzymes are designated $\alpha, \beta, \gamma$, $\delta$ and $\zeta$-CAs. $\alpha$-CAs are present in animals, some fungi, bacteria, algae, and cytoplasm of green plants. $\beta$-CAs are expressed mainly in fungi, bacteria, archaea, algae, and

\footnotetext{
* Correspondence: reza.zolfaghari.emameh@uta.fi

'School of Medicine, University of Tampere, Medisiinarinkatu 3, 33520

Tampere, Finland

${ }^{2}$ Institute of Biomedical Technology and BioMediTech, University of Tampere, 33520 Tampere, Finland

Full list of author information is available at the end of the article
}

chloroplasts of monocotyledons and dicotyledons. $\gamma$-CAs are expressed in plants, archaea, and some bacteria. $\delta$ - and $\zeta$-CAs are present in several classes of marine phytoplankton [1-6]. A total of 13 enzymatically active $\alpha$-CAs have been reported in mammals: CA I, CA II, CA III, CA VII, and CA XIII are cytosolic enzymes; CA IV, CA IX, CA XII, CA XIV, and CA XV are membrane-bound; CA VA and CA VB are mitochondrial; CA VI is secreted and CA VIII, CA $\mathrm{X}$, and CA XI are acatalytic CA-related proteins $[3,7]$. The active site of CA contains a zinc ion $\left(\mathrm{Zn}^{2+}\right)$ which has a critical role in the catalytic activity of the enzyme. $\zeta$-and $\gamma$-CAs represent exceptions to this rule since they can use 
cadmium $(\zeta)$, iron $(\gamma)$, or cobalt $(\gamma)$ as cofactors [8-10]. CAs are involved in many biological processes, such as respiration involving transport of $\mathrm{CO}_{2}$ and bicarbonate between metabolizing tissues, $\mathrm{pH}$ homeostasis, electrolyte transfer, bone resorption, calcification, and tumor progression. They also participate in some biosynthetic reactions, such as gluconeogenesis, lipogenesis, and ureagenesis [3,11-14].

The first $\beta$-CA was serendipitously discovered by Neish in 1939 [15]. In 1990, the cDNA sequence of spinach (Spinacea oleracea) chloroplast CA was determined, and found to be non-homologous to animal $\alpha-C A$ $[16,17]$. Thereafter, cDNA sequences of $\beta$-CA from pea (Pisium sativum) and Arabidopsis thaliana were determined [17-19]. It is believed that the plant $\beta$-CAs are distributed in the chloroplastic stroma, thylakoid space, and cytoplasm of plant cells [17]. Many putative $\beta$-CAs have been discovered since 1990, not only in photosynthetic organisms, but also in eubacteria, yeast, and archaea [17].

The first bacterial $\beta$-CA gene was named CynT and recognized in Escherichia coli [20,21]. Later, $\beta$-CA was identified in some other pathogenic bacteria, such as Helicobacter pylori, Mycobacterium tuberculosis, Salmonella typhimurium [17,22], Haemophilus influenzae [23,24], Brucella suis [24,25], Streptococcus pneumoniae [24,26], Salmonella enterica [24,27], and Vibrio cholerae [24,28,29]. $\beta$-CAs have also been identified in fungi, such as Candida albicans [1,30], Candida glabrata [1,31], Cryptococcus neoformans [1,32], and Sordaria macrospora [6,33]. This class of enzyme has also been discovered in a wide range of taxa, such as yeast (Saccharomyces cerevisiae) [34-36], cyanobacteria (Synechocystis sp. PCC6803) [37], carboxysomes of chemoautotrophic bacteria (Halothiobacillus neapolitanus) [38], green algae (Chlamydomonas reinhardtii) [39], red algae (Porphyridium purpureum) [40], nematodes (Caenorhabditis elegans) [41], and insects (Drosophila melanogaster) [4]. While $\beta$-CAs were initially thought to be expressed only in plants, this enzyme family is indeed present in a wide variety of species - from bacteria and archaea to invertebrate animals, missing only from vertebrates and most chordates, making it an attractive target for evolutionary studies [5].

$\beta-C A$ is an important accessory enzyme for many $\mathrm{CO}_{2}$ or $\mathrm{HCO}_{3}^{-}$utilizing enzymes (e.g. RuBisCO in chloroplasts, cyanase in E. coli [42], urease in H. pylori [43], and carboxylases in Corynebacterium glutamicum [44]). In cyanobacteria, $\beta-C A$ is an essential component of the $\mathrm{CO}_{2}$-concentrating carboxysome organelle $[17,45]$. $\beta$-CA activity is required for growth of $E$. coli bacteria in air [46]; it is also indispensable if the atmospheric partial pressure of $\mathrm{CO}_{2}$ is high or during anaerobic growth in a closed vessel at low $\mathrm{pH}$, where copious $\mathrm{CO}_{2}$ is generated endogenously. $\beta$-CA is also needed for growth of C. glutamicum $[44,47]$ and some yeasts, such as $S$. cerevisiae [40]. In higher plants, the Flaveria bidentis genome contains at least three
$\beta$-CA genes, named $C A 1, C A 2$, and $C A 3$ [48]. The functional roles of $\beta$-CAs in plants are not yet fully understood, even though a lot of new data has emerged in recent years. $\mathrm{C}_{3}$ and $\mathrm{C}_{4}$ plants have different mechanisms for carbon fixation and photosynthesis and, thus, $\beta$-CAs might possess different roles, depending on the location of the enzyme and the type of plant [49]. In plants, the highest CA activity has been found within the chloroplast stroma, but there is also some CA activity in the cytosol of mesophyll cells [50]. Carbon dioxide coming from the external environment must be rapidly hydrated by $\beta-\mathrm{CA}$ and converted into $\mathrm{HCO}_{3}^{-}$for the phosphoenolpyruvate carboxylase enzyme [49]. Additionally, CAs play a role in photosynthesis by facilitating diffusion into and across the chloroplast, and by catalyzing $\mathrm{HCO}_{3}^{-}$dehydration to supply $\mathrm{CO}_{2}$ for RuBisCO. Interestingly, both $\mathrm{RuBisCO}$ and $\beta-\mathrm{CA}$ expression levels increase together when $P$. sativum is transferred from an environment with high levels of $\mathrm{CO}_{2}$ to one with low levels [47].

Crystal structures of $\beta$-CAs reveal that a zinc ion $\left(\mathrm{Zn}^{2+}\right)$ is ligated by two conserved cysteines and one conserved histidine [5]. Until now, the only X-ray crystallography structure defined for $\beta$-CAs in plants belongs to P. sativum [51]. E. coli was the first bacteria in which the $\beta$-CA crystal structure was determined [20]. $\beta$-CA can adopt a variety of oligomeric states with molecular masses ranging from 45 to $200 \mathrm{kDa}$ [52].

The first metazoan $\beta$-CAs were reported in 2010 [41]. In one of the studies [4,41], two genes encoding $\beta$-CAs (y116a8c.28 and bca-1) were identified in Caenorhabditis elegans. Another study reported a novel $\beta$-CA gene identified from FlyBase, which was named DmBCA (short for Drosophila melanogaster $\beta$-CA) [4]. Additionally, orthologs were retrieved from sequence databases, and reconstructed when necessary. The results confirmed the presence of $\beta$-CA sequences in 55 metazoan species, such as Aedes aegypti, Culex quinquefasciatus, Anopheles gambiae, Drosophila virilis, Tribolium castaneum, Nasonia vitripennis, Apis mellifera, Acyrthosiphon pisum, Daphnia pulex, Caenorhabditis elegans, Pristionchus pacificus, Trichoplax adhaerens, Caligus clemensi, Lepeophtheirus salmonis, Nematostella vectensis, Strongylocentrotus purpuratus, and Saccoglossus kowalevskii. The DmBCA enzyme was produced as a recombinant protein in Sf9 insect cells, and its kinetic and inhibition profiles were determined. The enzyme showed high $\mathrm{CO}_{2}$ hydratase activity, with a $\mathrm{k}_{\text {cat }}$ of $9.5 \times 10^{5} \mathrm{~s}^{-1}$ and a $\mathrm{k}_{\text {cat }} / \mathrm{K}_{\mathrm{M}}$ of $1.1 \times$ $10^{8} \mathrm{M}^{-1} \mathrm{~s}^{-1}$. DmBCA was inhibited by the clinically-used sulfonamide, acetazolamide, with an inhibition constant of $49 \mathrm{nM}$. Subcellular localization studies have indicated that DmBCA is probably a mitochondrial enzyme, as is also suggested by sequence analysis.

In this study, using bioinformatics tools, we discovered and verified the presence of $\beta-\mathrm{CA}$ in various other 
metazoan species, and, for the first time, in protozoa. Previously, most $\beta$-CA proteins have been identified in protein databases as 'unknown' proteins or 'putative' CAs, without a specific reference to $\beta$-CAs. Based on the present findings, new avenues will be opened to biochemically characterize $\beta$-CAs and their inhibitors in arthropods, nematodes and protozoans.

\section{Methods}

Identification of putative $\beta$-CA enzymes in protozoan and metazoan species and multiple sequence alignment

Identification of novel $\beta$-CAs was based on the presence of the highly-conserved amino acid sequence patterns of the active site, namely Cys-Xaa-Asp-Xaa-Arg and HisXaa-Xaa-Cys also marked in Additional file 1: Figure S1. Alignment was visualized in Jalview [53]. In total, 75 invertebrate $\beta$-CA sequences were retrieved from Uniprot (http://www.uniprot.org/) for alignment analysis, and one bacterial sequence (Pelosinus fermentans) was included as an outgroup. All protein sequences were aligned using Clustal Omega (http://www.ebi.ac.uk/Tools/msa/clustalo/) [54]. The sequences were manually curated to remove residues associated with an incorrect starting methionine. A total of 90 residues were removed from the $\mathrm{N}$-terminal end of Uniprot IDs D4NWE5_ADIVA, G0QPN9_ICHMG, D6WK56_TRICA, I7LWM1_TETTS and I7M0M0_TETTS. The modified protein sequences were then re-aligned. This protein alignment then served as the template for codon alignment of corresponding nucleotide sequences using the Pal2Nal program (http://www.bork.embl.de/pal2nal/) [55].

\section{Phylogenetic analysis}

The phylogenetic analysis was computed using Mr. Bayes v3.2 [56]. After 8 million generations using the GTR codon substitution model, with all other parameters as default, the standard deviation of split frequencies was $1.39 \times 10^{-3}$. The final output tree was produced using 50\% majority rule consensus. FigTree v1.4.0 (http://tree. bio.ed.ac.uk/software/figtree/) [56] was used to visualize the phylogenetic tree and the Pelosinus fermentans [57] sequence set as outgroup. Additional trees were constructed for comparison using maximum likelihood (PhyML)[58], UPGMA, and neighbor-joining methods within Geneious version 7.0.5 from Biomatters (Auckland, New Zealand) (http://www.geneious.com/).

\section{Prediction of subcellular localization}

Subcellular localization prediction of each identified invertebrate $\beta$-CA was performed using the TargetP webserver (http://www.cbs.dtu.dk/services/TargetP/). TargetP is built from two layers of neural networks, where the first layer contains one dedicated network for each type of pre-sequence [cTP (cytoplasmic targeting peptide), mTP (mitochondrial targeting peptide, or SP (secretory signal peptide)], and the second is an integrating network that outputs the actual prediction (cTP, mTP, SP, other). It is able to discriminate between cTPs, mTPs, and SPs with sensitivities and specificities higher than what has been obtained with other available subcellular localization predictors [59].

\section{Results}

\section{Multiple sequence alignment}

The Uniprot search of potential $\beta$-CA sequences, and the subsequent multiple sequence alignment, identified $75 \beta$-CAs in metazoan and protozoan species, of which 23 sequences were reported as $\beta$-CAs previously [4]. Thus, 52 metazoan and protozoan $\beta$-CA sequences were novel and reported here for the first time. All $75 \beta$-CAs in metazoan and protozoan species are shown in Table 1. The multiple sequence alignment results of these $75 \beta$ CAs, plus a bacterial $\beta$-CA sequence from Pelosinus fermentans, are shown as Additional file 1: Figure S1. Multiple sequence alignment of all animal $\beta$-CAs confirmed conservation of the known active site motifs CxDxR and HxxC in all identified enzymes. Several other key residues were also highly conserved. Notably, all $\beta$-CA sequences from Leishmania species (Leishmania donovani, Leishmania infantum, Leishmania major, and Leishmania mexicana) contained a 71 residue N-terminal extension not present in any other sequences.

\section{Phylogenetic analysis}

The results of the phylogenetic analysis of $75 \beta$-CAs in metazoan and protozoan species are shown in Figure 1. A $\beta$-CA sequence from the Pelosinus fermentans bacterium was used as an outgroup [60]. The phylogenetic results represent the evolutionary root of $\beta$-CAs in metazoan and protozoan species, the similarity between them, and duplications that have occurred. The branching pattern and branch lengths reveal interesting evolutionary relationships of $\beta$-CAs in various invertebrate species. There is a close relationship between our bacterial outgroup and Trichomonas vaginalis $\beta$-CAs, both having originated well before the other species within the tree. $\beta$-CAs of nematodes and arthropods are located in the lower evolutionary branches. In the protozoan Tetrahymena thermophilia and Paramecium tetraurelia clades significant duplications of $\beta$-CA have occurred, with 8 and 5 distinct proteins respectively. Meanwhile, metazoan and nematode species tend to have just one or two $\beta$-CAs. Surprisingly, $\beta$-CAs of the nematode Trichinella spiralis and trematode Schistosoma mansoni appear more closely related to arthropod than to nematode enzymes. The triangle located near the bottom of Figure 1 represents the clade of $\beta$-CAs in different Drosophila species. The details of the phylogenetic tree of $\beta$-CAs in Drosophila species are shown in Figure 2. The likely presence of inaccuracies in some of the database 
Table 1 Identified $\beta$-CAs in protozoan and metazoan species

\begin{tabular}{|c|c|c|c|c|}
\hline Species & $\beta$ - CA ID & Entry ID & Gene name & Protein name \\
\hline Acromyrmex echinatior & BCA & F4WAG3 & G5I_02499 & Beta carbonic anhydrase 1 \\
\hline \multirow[t]{3}{*}{ Acyrthosiphon pisum } & BCA1 & J9K706 & Uncharacterized & Uncharacterized \\
\hline & BCA2 & C4WVD8 & ACYPI006033 & ACYPI006033 \\
\hline & BCA3 & J9JZY3 & XM_001950078.1 & Uncharacterized \\
\hline Adineta vaga & BCA & D4NWE5 & Uncharacterized & Putative uncharacterized protein \\
\hline Aedes aegypti & $\mathrm{BCA}$ & Q17N64 & AAEL000816 & AAEL000816-PA \\
\hline Ancylostoma caninum & BCA & FC551456 & Uncharacterized & Uncharacterized protein \\
\hline Anopheles darlingi & BCA & $\mathrm{E} 3 \times 5 \mathrm{Q} 8$ & AND_14274 & Uncharacterized protein \\
\hline Anopheles gambiae & BCA & Q5TU56 & AGAP002992 AgaP_AGAP002992 & AGAP002992-PA \\
\hline Apis mellifera & $\mathrm{BCA}$ & H9KS29 & Uncharacterized & Uncharacterized protein \\
\hline Ascaris suum & BCA & F1LE18 & Uncharacterized & Beta carbonic anhydrase 1 \\
\hline \multirow[t]{2}{*}{ Caenorhabditis brenneri } & BCA1 & G0MSW4 & Cbn-bca-1 CAEBREN_17105 & CBN-BCA-1 protein \\
\hline & BCA2 & GOMRG1 & Cbn-bca-2 CAEBREN_06024 & CBN-BCA-2 protein \\
\hline \multirow[t]{2}{*}{ Caenorhabditis briggsae } & BCA1 & A8XKV0 & bca-1 CBG14861 & Beta carbonic anhydrase 1 \\
\hline & BCA2 & A8WN21 & bca-2 Cbr-bca-2 cbr-bca-2 CBG00424 CBG_00424 & Protein CBR-BCA-2 \\
\hline \multirow[t]{2}{*}{ Caenorhabditis elegans } & BCA1 & Q22460 & bca-1 T13C5.5 & Beta carbonic anhydrase 1 \\
\hline & BCA2 & Q2YS41 & bca-2 Y116A8C.28 & Protein BCA-2 \\
\hline \multirow[t]{2}{*}{ Caenorhabditis remanei } & BCA1 & E3LDN3 & Cre-bca-1 CRE_00190 & CRE-BCA-1 protein \\
\hline & BCA2 & E3MK96 & Cre-bca-2 CRE_28742 & CRE-BCA-2 protein \\
\hline Caligus clemensi & BCA & $\mathrm{C} 1 \mathrm{C} 2 \mathrm{M} 7$ & CYNT & Carbonic anhydrase \\
\hline Camponotus floridanus & BCA & E2ANQ9 & EAG_05651 & Carbonic anhydrase \\
\hline Culex quinquefasciatus & BCA & BOWKV7 & CpipJ_CPIJ007527 & Carbonic anhydrase \\
\hline Danaus plexippus & $\mathrm{BCA}$ & G6D7Z4 & Uncharacterized & Putative carbonic anhydrase \\
\hline Daphnia pulex & BCA & E9GLB5 & $C A B$ & Beta-carbonic anhydrase \\
\hline Dendroctonus ponderosae & BCA & J3JTM9 & Uncharacterized & Uncharacterized protein \\
\hline Drosophila ananassae & BCA & B3LZ10 & GF17694 DanalGF17694 Dana_GF17694 & GF17694 \\
\hline Drosophila erecta & $\mathrm{BCA}$ & B3P1V8 & GG13874 DerelGG13874 Dere_GG13874 & GG13874 \\
\hline Drosophila grimshawi & BCA & B4JHY1 & GH19010 Dgri\GH19010 Dgri_GH19010 & GH19010 \\
\hline Drosophila melanogaster & BCA & Q9VHJ5 & CAHbeta CG11967 Dmel_CG11967 & CG11967 \\
\hline Drosophila mojavensis & $B C A$ & B4KDC1 & GI23065 Dmoj\GI23065 Dmoj_GI23065 & Gl23065 \\
\hline Drosophila persimilis & BCA & B4GFA1 & GL22171 Dper\GL22171 Dper_GL22171 & GL22171 \\
\hline Drosophila pseudoobscura & BCA & Q296E4 & GA11301 DpselGA11301 Dpse_GA11301 & GA11301 \\
\hline Drosophila sechellia & $B C A$ & B4HKY7 & GM23772 DseclGM23772 Dsec_GM23772 & GM23772 \\
\hline Drosophila simulans & BCA & $\mathrm{B} 4 \mathrm{QXC5}$ & GD18582 Dsim\GD18582 Dsim_GD18582 & GD18582 \\
\hline Drosophila virilis & $\mathrm{BCA}$ & B4LZE7 & CAHbeta Dvir\GJ24578 GJ24578 Dvir_GJ24578 & GJ24578 \\
\hline Drosophila willistoni & BCA & B4NBB9 & GK11865 Dwil\GK11865 Dwil_GK11865 & GK11865 \\
\hline Drosophila yakuba & BCA & B4PTYO & GE25916 Dyak\GE25916 Dyak_GE25916 & GE25916 \\
\hline Entamoeba dispar & BCA & BOE7MO & EDI_275880 & Carbonic anhydrase \\
\hline Entamoeba histolytica & BCA & C4LXK3 & EHI_073380 & Carbonic anhydrase \\
\hline Entamoeba nuttalli & BCA & K2GQM0 & ENU1_204230 & $\begin{array}{l}\text { Carbonate dehydratase domain } \\
\text { containing protein }\end{array}$ \\
\hline Harpegnathos saltator & BCA & E2B2Q1 & EAI_05019 & Carbonic anhydrase \\
\hline Heliconius melpomene & BCA & HMEL015257 & Uncharacterized & Uncharacterized protein \\
\hline Hirudo medicinalis & $B C A$ & EY481200 & Uncharacterized & Uncharacterized protein \\
\hline
\end{tabular}


Table 1 Identified $\boldsymbol{\beta}$-CAs in protozoan and metazoan species (Continued)

\begin{tabular}{|c|c|c|c|c|}
\hline Ichthyophthirius multifiliis & BCA & G0QPN9 & IMG5_069900 & Carbonic anhydrase \\
\hline Leishmania donovani & BCA & E9B8S3 & LDBPK_060630 & Carbonic anhydrase \\
\hline Leishmania infantum & $\mathrm{BCA}$ & A4HSV2 & LINJ_06_0630 & Carbonic anhydrase \\
\hline Leishmania major & $\mathrm{BCA}$ & Q4QJ17 & LMJF_06_0610 & Carbonic anhydrase \\
\hline Leishmania mexicana & $\mathrm{BCA}$ & E9AKU0 & LMXM_06_0610 & Carbonic anhydrase \\
\hline Lepeophtheirus salmonis & $\mathrm{BCA}$ & D3PI48 & BCA1 & Beta carbonic anhydrase 1 \\
\hline Nasonia vitripennis & $\mathrm{BCA}$ & K7IWK8 & Uncharacterized & Uncharacterized protein \\
\hline Nematostella vectensis & $\mathrm{BCA}$ & A7S717 & v1g186479 & Predicted protein \\
\hline \multirow[t]{5}{*}{ Paramecium tetraurelia } & BCA1 & A0BD61 & GSPATT00004572001 & Carbonic anhydrase \\
\hline & BCA2 & A0E8J0 & GSPATT00024336001 & Carbonic anhydrase \\
\hline & BCA3 & A0CEX6 & GSPATT00037782001 & Carbonic anhydrase \\
\hline & BCA4 & AOBDB1 & GSPATT00004622001 & Carbonic anhydrase \\
\hline & BCA5 & A0C922 & GSPATT00006595001 & Carbonic anhydrase \\
\hline Saccoglossus kowalevskii & BCA & 187043763 & Uncharacterized & Uncharacterized protein \\
\hline Schistosoma mansoni & $\mathrm{BCA}$ & G4V6B2 & Smp_004070 & Putative carbonic anhydrase \\
\hline Solenopsis invicta & BCA & E9IP13 & SINV_09652 & Putative carbonic anhydrase \\
\hline Strigamia maritima & BCA & SMAR006741 & Uncharacterized & Uncharacterized protein \\
\hline Strongylocentrotus purpuratus & $\mathrm{BCA}$ & H31177 & Uncharacterized & Uncharacterized protein \\
\hline \multirow[t]{8}{*}{ Tetrahymena thermophila } & BCA1 & Q22U21 & TTHERM_00263620 & Carbonic anhydrase \\
\hline & BCA2 & Q22U16 & TTHERM_00263670 & Carbonic anhydrase \\
\hline & BCA3 & I7MDL7 & TTHERM_00373840 & Carbonic anhydrase \\
\hline & BCA4 & I7LWM1 & TTHERM_00558270 & Carbonic anhydrase \\
\hline & BCA5 & I7MOMO & TTHERM_00374880 & Carbonic anhydrase \\
\hline & BCA6 & 17MD92 & TTHERM_00541480 & Carbonic anhydrase \\
\hline & BCA7 & 17M748 & TTHERM_00374870 & Carbonic anhydrase \\
\hline & BCA8 & Q23AV1 & TTHERM_00654260 & Carbonic anhydrase \\
\hline Tribolium castaneum & BCA & D6WK56 & TcasGA2_TC014816 & Putative uncharacterized protein \\
\hline Trichinella spiralis & BCA & E5SH53 & Uncharacterized & Carbonic anhydrase \\
\hline \multirow[t]{2}{*}{ Trichomonas vaginalis } & BCA1 & A2ENQ8 & TVAG_005270 & Carbonic anhydrase \\
\hline & BCA2 & A2DLG4 & TVAG_268150 & Carbonic anhydrase \\
\hline Trichoplax adhaerens & BCA & $\mathrm{B} 3 \mathrm{~S} 5 \mathrm{Y} 1$ & TRIADDRAFT_29634 & Putative uncharacterized protein \\
\hline Xenoturbella bocki & BCA & 117195962 & Uncharacterized & Uncharacterized protein \\
\hline
\end{tabular}

sequences, and inherent limitations of Bayesian inference, prompted use of additional phylogenetic methods. These analyses generally supported the major features of the final tree achieved via Bayesian inference.

\section{Subcellular localization of $\beta$-CAs}

The predictions for subcellular localization of the 75 $\beta$-CAs are shown in Table 2 . The results reveal that 31 are predicted to have a mitochondrial localization, one (Anopheles darlingi, Uniprot ID: E3X5Q8) was predicted to be secreted, and the remaining 43 were predicted to have other cellular localizations. The predictions were based on the analysis of $175 \mathrm{~N}$-terminal amino acids of each sequence. In the Name column, there are both
IDs of the $\beta$-CAs in Uniprot database and scientific name of the metazoan and protozoan species.

\section{Discussion}

This study shows that the $\beta$-CA enzyme is present in a range of protozoans and metazoans. A total of 75 sequences were identified and a phylogenetic tree constructed. The multiple sequence alignment results revealed that all 75 sequences have the highly conserved residues (Cysteine, Aspartic acid, Arginine, and Histidine) consistent with a $\beta$-CA enzyme (Additional file 1: Figure S1). Most of the metazoan and protozoan $\beta$-CAs, and corresponding coding sequences, were designated as uncharacterized sequences or CAs with no class specification. These 


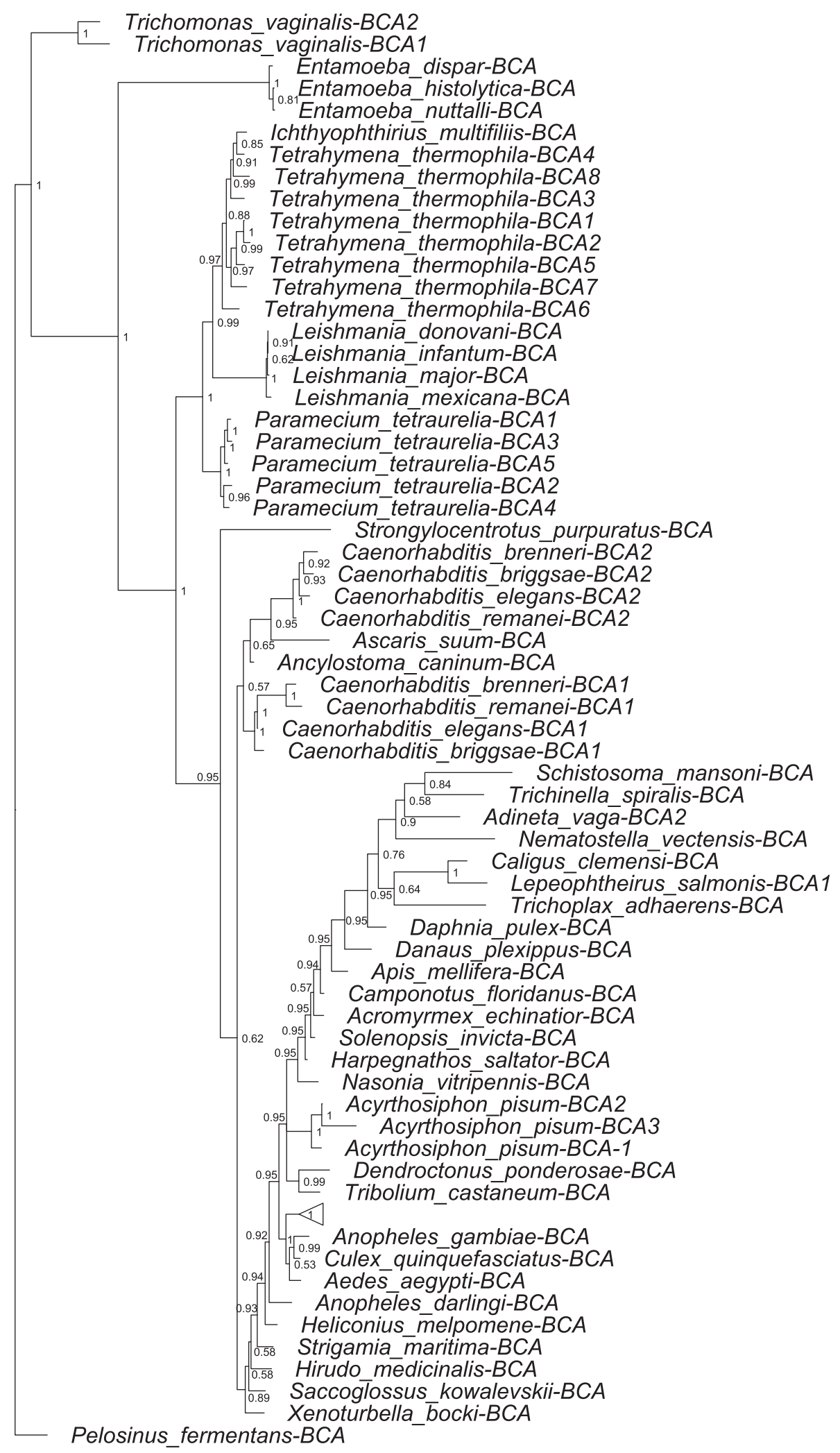

Figure 1 Phylogenetic analysis of $\mathbf{7 5}$ metazoan and protozoan $\beta$-CAs. The position of $\beta$-CAs of Drosophila species has been represented at the bottom of the phylogenetic tree by a triangle shape. The details of $\beta$-CAs of Drosophila species in the phylogenetic tree are shown in Figure 2. 
can be now assigned to $\beta$-CAs in proteomics and genomics databases.

$\beta$-CAs have been identified in the mitochondria of a variety of different organisms, such as plants [61], green algae [62], fungi [1,63], and Drosophila melanogaster [4]. Our results of subcellular localization prediction (Table 2) suggested that 31 of the $\beta$-CAs are targeted to mitochondria. In mitochondrial targeting peptides (mTPs), Arginine, Alanine and Serine are over-represented, while negatively charged amino acid residues (Aspartic acid and Glutamic acid) are rare. Furthermore, mTPs are believed to form an amphiphilic $\alpha$-helix, which is important for the import of the nascent protein into the mitochondrion [59]. The successful construction of the TargetP predictor demonstrates that protein sorting signals can be recognized with reasonable reliability from amino acid sequence data alone, thus, to some extent, mimicking the cellular recognition processes [59]. The prediction of the mitochondrial localization for many of the proteins studied is also supported by the previous experimental data, showing that recombinant $\mathrm{DmBCA}$ protein is indeed located in mitochondria of insect cells [4]. As mitochondrial proteins the $\beta$-CAs may contribute to key metabolic functions. Among the mammalian $\alpha$-CAs, CA VA and CA VB are the only enzymes that have been exclusively located to mitochondria. Functional studies, summarized in [64], have indicated them in several metabolic processes, such as gluconeogenesis, urea synthesis, and fatty acid synthesis. It has been shown previously that the gluconeogenic enzyme, pyruvate carboxylase, is expressed in protozoan (Toxoplasma gondii) mitochondria [65]. This enzyme utilizes bicarbonate to convert pyruvate to oxaloacetate. Mitochondrial CA V is also involved in lipid synthesis through pyruvate carboxylation reaction [66]. Importantly, lipid metabolism is of crucial importance for parasites. Lipids serve as cellular building blocks, signaling

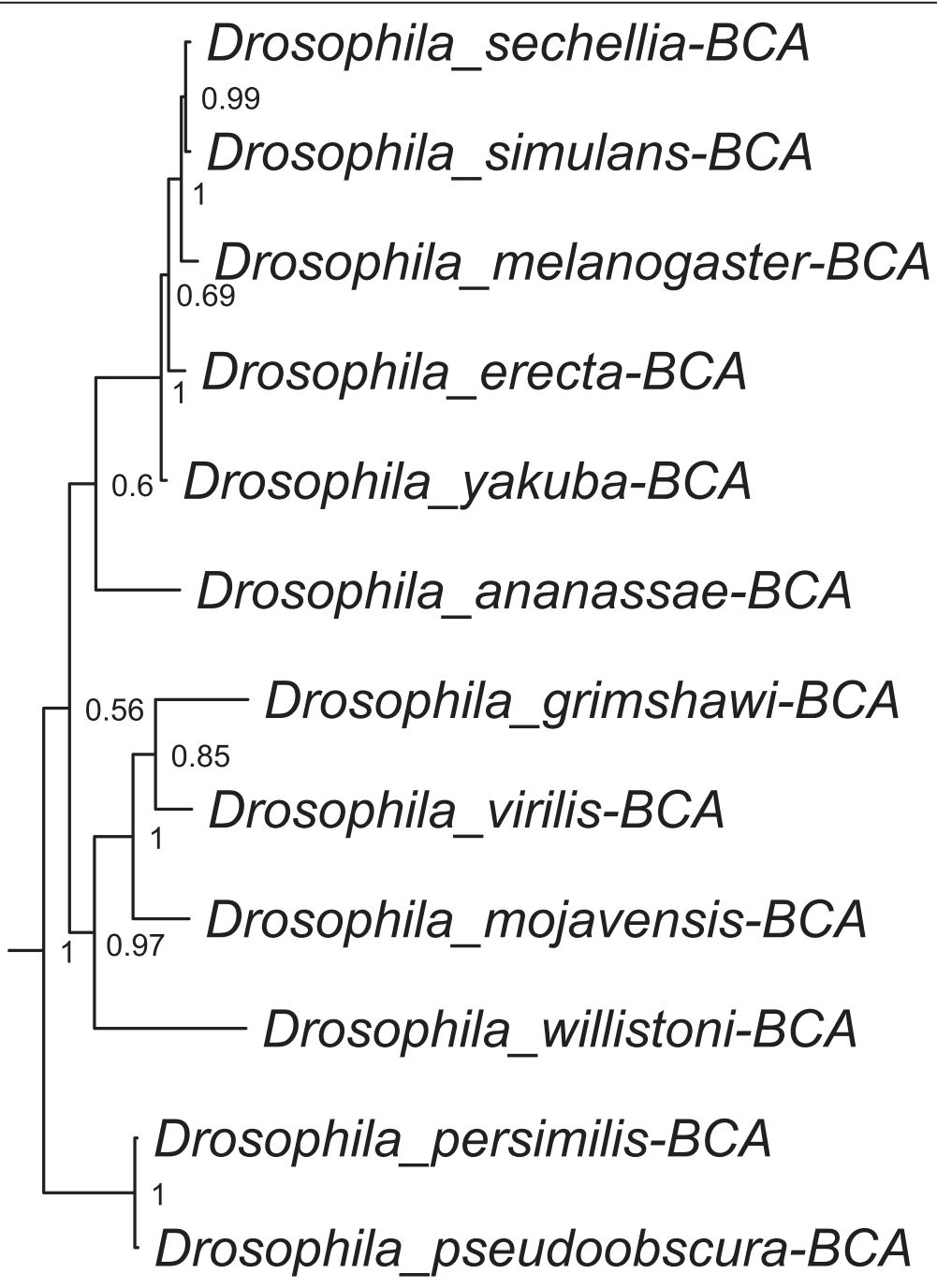

Figure 2 Phylogenetic analysis of $\beta$-CAs of Drosophila species. This tree represents the expanded view of the triangle located near the bottom of the main phylogenetic tree of $\beta$-CAs in Figure 1. 
Table 2 Prediction of the subcellular localization of $75 \beta$-CAs of metazoan and protozoan species

\begin{tabular}{|c|c|c|c|c|c|c|c|}
\hline Species & $\beta-C A$ ID & Entry ID & mTP & SP & Other & Loc & $\mathrm{RC}$ \\
\hline Acromyrmex echinatior & BCA & F4WAG3 & 0.199 & 0.054 & 0.86 & - & 2 \\
\hline \multirow[t]{3}{*}{ Acyrthosiphon pisum } & BCA1 & J9K706 & 0.473 & 0.05 & 0.631 & - & 5 \\
\hline & BCA2 & C4WVD8 & 0.579 & 0.043 & 0.536 & M & 5 \\
\hline & BCA3 & J9JZY3 & 0.579 & 0.043 & 0.534 & M & 5 \\
\hline Adineta vaga & $B C A$ & D4NWE5 & 0.509 & 0.102 & 0.375 & M & 5 \\
\hline Aedes aegypti & $B C A$ & Q17N64 & 0.589 & 0.029 & 0.491 & M & 5 \\
\hline Ancylostoma caninum & BCA & FC551456 & 0.466 & 0.046 & 0.514 & - & 5 \\
\hline Anopheles darlingi & $\mathrm{BCA}$ & E3X5Q8 & 0.044 & 0.836 & 0.144 & $S$ & 2 \\
\hline Anopheles gambiae & BCA & Q5TU56 & 0.713 & 0.03 & 0.34 & M & 4 \\
\hline Apis mellifera & BCA & H9KS29 & 0.126 & 0.08 & 0.875 & - & 2 \\
\hline Ascaris suum & BCA & F1LE18 & 0.388 & 0.079 & 0.406 & - & 5 \\
\hline \multirow[t]{2}{*}{ Caenorhabditis brenneri } & BCA1 & GOMSW4 & 0.522 & 0.036 & 0.518 & M & 5 \\
\hline & BCA2 & G0MRG1 & 0.52 & 0.051 & 0.473 & M & 5 \\
\hline \multirow[t]{2}{*}{ Caenorhabditis briggsae } & BCA1 & A8XKV0 & 0.392 & 0.047 & 0.615 & - & 4 \\
\hline & BCA2 & A8WN21 & 0.546 & 0.048 & 0.466 & M & 5 \\
\hline \multirow[t]{2}{*}{ Caenorhabditis elegans } & BCA1 & Q22460 & 0.475 & 0.039 & 0.549 & - & 5 \\
\hline & BCA2 & Q2YS41 & 0.465 & 0.05 & 0.529 & - & 5 \\
\hline \multirow[t]{2}{*}{ Caenorhabditis remanei } & BCA1 & E3LDN3 & 0.327 & 0.045 & 0.69 & - & 4 \\
\hline & BCA2 & E3MK96 & 0.51 & 0.051 & 0.48 & M & 5 \\
\hline Caligus clemensi & BCA & $\mathrm{C} 1 \mathrm{C} 2 \mathrm{M} 7$ & 0.21 & 0.04 & 0.873 & - & 2 \\
\hline Camponotus floridanus & $\mathrm{BCA}$ & E2ANQ9 & 0.325 & 0.051 & 0.735 & - & 3 \\
\hline Culex quinquefasciatus & $\mathrm{BCA}$ & BOWKV7 & 0.573 & 0.032 & 0.507 & M & 5 \\
\hline Danaus plexippus & $\mathrm{BCA}$ & G6D7Z4 & 0.793 & 0.032 & 0.273 & M & 3 \\
\hline Daphnia pulex & BCA & E9GLB5 & 0.157 & 0.055 & 0.843 & - & 2 \\
\hline Dendroctonus ponderosae & BCA & J3JTM9 & 0.27 & 0.064 & 0.742 & - & 3 \\
\hline Drosophila ananassae & $\mathrm{BCA}$ & B3LZ10 & 0.537 & 0.041 & 0.518 & M & 5 \\
\hline Drosophila erecta & BCA & B3P1V8 & 0.531 & 0.04 & 0.53 & M & 5 \\
\hline Drosophila grimshawi & BCA & B4JHY1 & 0.605 & 0.037 & 0.454 & M & 5 \\
\hline Drosophila melanogaster & BCA & Q9VHJ5 & 0.531 & 0.04 & 0.53 & M & 5 \\
\hline Drosophila mojavensis & BCA & B4KDC1 & 0.556 & 0.039 & 0.511 & M & 5 \\
\hline Drosophila persimilis & $\mathrm{BCA}$ & B4GFA1 & 0.595 & 0.037 & 0.466 & M & 5 \\
\hline Drosophila pseudoobscura & $\mathrm{BCA}$ & Q296E4 & 0.595 & 0.037 & 0.466 & M & 5 \\
\hline Drosophila sechellia & BCA & B4HKY7 & 0.531 & 0.04 & 0.53 & M & 5 \\
\hline Drosophila simulans & $\mathrm{BCA}$ & B4QXC5 & 0.531 & 0.04 & 0.53 & M & 5 \\
\hline Drosophila virilis & $\mathrm{BCA}$ & B4LZE7 & 0.531 & 0.04 & 0.53 & M & 5 \\
\hline Drosophila willistoni & $\mathrm{BCA}$ & B4NBB9 & 0.531 & 0.04 & 0.53 & M & 5 \\
\hline Drosophila yakuba & BCA & B4PTYO & 0.531 & 0.04 & 0.53 & M & 5 \\
\hline Entamoeba dispar & $\mathrm{BCA}$ & BOE7MO & 0.114 & 0.158 & 0.766 & - & 2 \\
\hline Entamoeba histolytica & BCA & C4LXK3 & 0.113 & 0.151 & 0.779 & - & 2 \\
\hline Entamoeba nuttalli & $\mathrm{BCA}$ & K2GQM0 & 0.132 & 0.142 & 0.763 & - & 2 \\
\hline Harpegnathos saltator & $\mathrm{BCA}$ & E2B2Q1 & 0.248 & 0.055 & 0.801 & - & 3 \\
\hline Heliconius melpomene & $\mathrm{BCA}$ & HMEL015257 & 0.77 & 0.032 & 0.302 & M & 3 \\
\hline Hirudo medicinalis & $\mathrm{BCA}$ & EY481200 & 0.121 & 0.098 & 0.778 & - & 2 \\
\hline Ichthyophthirius multifiliis & BCA & G0QPN9 & 0.181 & 0.04 & 0.872 & - & 2 \\
\hline
\end{tabular}


Table 2 Prediction of the subcellular localization of $75 \boldsymbol{\beta}$-CAs of metazoan and protozoan species (Continued)

\begin{tabular}{|c|c|c|c|c|c|c|c|}
\hline Leishmania donovani & $\mathrm{BCA}$ & E9B8S3 & 0.106 & 0.13 & 0.826 & - & 2 \\
\hline Leishmania infantum & $\mathrm{BCA}$ & A4HSV2 & 0.106 & 0.13 & 0.826 & - & 2 \\
\hline Leishmania major & $B C A$ & Q4QJ17 & 0.108 & 0.124 & 0.822 & - & 2 \\
\hline Leishmania mexicana & $\mathrm{BCA}$ & E9AKU0 & 0.109 & 0.135 & 0.82 & - & 2 \\
\hline Lepeophtheirus salmonis & BCA & D3PI48 & 0.126 & 0.068 & 0.889 & - & 2 \\
\hline Nasonia vitripennis & $\mathrm{BCA}$ & K7IWK8 & 0.388 & 0.046 & 0.713 & - & 4 \\
\hline Nematostella vectensis & BCA & A7S717 & 0.775 & 0.052 & 0.211 & M & 3 \\
\hline \multirow[t]{5}{*}{ Paramecium tetraurelia } & BCA1 & A0BD61 & 0.196 & 0.045 & 0.843 & - & 2 \\
\hline & BCA2 & A0E8J0 & 0.107 & 0.056 & 0.909 & - & 1 \\
\hline & BCA3 & A0CEX6 & 0.28 & 0.045 & 0.725 & - & 3 \\
\hline & BCA4 & A0BDB1 & 0.073 & 0.065 & 0.938 & - & 1 \\
\hline & BCA5 & A0C922 & 0.178 & 0.056 & 0.826 & - & 2 \\
\hline Saccoglossus kowalevskii & $\mathrm{BCA}$ & 187043763 & 0.565 & 0.049 & 0.463 & M & 5 \\
\hline Schistosoma mansoni & BCA & G4V6B2 & 0.388 & 0.064 & 0.605 & - & 4 \\
\hline Solenopsis invicta & $\mathrm{BCA}$ & E9IP13 & 0.326 & 0.052 & 0.756 & - & 3 \\
\hline Strigamia maritima & $\mathrm{BCA}$ & SMAR006741 & 0.683 & 0.046 & 0.28 & M & 3 \\
\hline Strongylocentrotus purpuratus & $\mathrm{BCA}$ & $\mathrm{H} 31177$ & 0.804 & 0.047 & 0.16 & M & 2 \\
\hline \multirow[t]{8}{*}{ Tetrahymena thermophila } & BCA1 & Q22U21 & 0.092 & 0.064 & 0.92 & - & 1 \\
\hline & BCA2 & Q22U16 & 0.087 & 0.075 & 0.918 & - & 1 \\
\hline & BCA3 & 17MDL7 & 0.659 & 0.067 & 0.203 & M & 3 \\
\hline & BCA4 & I7LWM1 & 0.115 & 0.058 & 0.871 & - & 2 \\
\hline & BCA5 & I7MOMO & 0.087 & 0.034 & 0.947 & - & 1 \\
\hline & BCA6 & I7MD92 & 0.058 & 0.069 & 0.941 & - & 1 \\
\hline & BCA7 & 17M748 & 0.09 & 0.047 & 0.933 & - & 1 \\
\hline & BCA8 & Q23AV1 & 0.187 & 0.123 & 0.758 & - & 3 \\
\hline Tribolium castaneum & $\mathrm{BCA}$ & D6WK56 & 0.054 & 0.097 & 0.938 & - & 1 \\
\hline Trichinella spiralis & BCA & E5SH53 & 0.876 & 0.028 & 0.177 & M & 2 \\
\hline \multirow[t]{2}{*}{ Trichomonas vaginalis } & BCA1 & A2ENQ8 & 0.043 & 0.137 & 0.933 & - & 2 \\
\hline & BCA2 & A2DLG4 & 0.073 & 0.061 & 0.937 & - & 1 \\
\hline Trichoplax adhaerens & $\mathrm{BCA}$ & B3S5Y1 & 0.582 & 0.038 & 0.459 & M & 5 \\
\hline Xenoturbella bocki & BCA & 117195962 & 0.222 & 0.056 & 0.78 & - & 3 \\
\hline
\end{tabular}

molecules, energy stores, posttranslational modifiers, and pathogenesis factors [67]. Parasites rely on complex metabolic systems to satisfy their lipid needs. The present findings open a new avenue to investigate whether mitochondrial $\beta$-CAs are functionally involved in these processes.

The single $\beta$-CA of Anopheles darlingi is the first predicted secretory $\beta$-CA. Among the various $\alpha$-CAs, the first secreted form (CA VI) was identified in human saliva in 1987 [68], and in 2011 another $\alpha$-CA was identified in the salivary gland of Aedes aegypti [69]. Complementary research, such as morphological, biochemical, and spatial mapping of gene expression in Anopheles darlingi will clarify the exact expression pattern of $\beta$-CA in this mosquito $[69,70]$.
The TargetP predictor defined $43 \beta$-CAs with 'other' cellular localizations. Although it is possible that $\beta$-CAs are truly located in different subcellular compartments depending on the species, these results should be interpreted with caution. Both the common errors in full genomic DNA, cDNA, or protein sequences in databases, and the potential inaccuracy of TargetP predictor could contribute to the observed deviations of the results. The highest prediction accuracy, with appropriate selection of specificity and sensitivity, is $90 \%$ [59].

Among the species mentioned in Table 1, some have important medical relevance, such as Aedes aegypti, Anopheles darlingi, Anopheles gambiae, Ascaris suum (Ascaris lumbricoides), Culex quinquefasciatus, Entamoeba histolytica, Hirudo medicinalis, Leishmania species, 
Schistosoma mansoni, Trichinella spiralis, and Trichomonas vaginalis. In the past decade, inhibition profiles of $\beta$-CAs of bacteria $[24,31,71]$ and fungi $[72-75]$ have been investigated with various inhibitors. Our results suggest that various protozoans and metazoans express $\beta$-CAs and that these molecules represent protein targets appropriate for inhibitor development. These proteins are not restricted to nematodes, insects, or protozoa causing human diseases, but are also present in many species with relevance to agriculture or veterinary medicine. These species include: Acyrthosiphon pisum, Ancylostoma caninum, Ascaris suum, Caligus clemensi, Camponotus floridanus, Culex quinquefasciatus, Dendroctonus ponderosae, Entamoeba species, Ichthyophthirius multifiliis, Solenopsis invicta, Tribolium castaneum, Trichinella spiralis, and Trichoplax adhaerens. Therefore, our findings also suggest that it might be possible to develop specific $\beta$-CA inhibitors as pesticides for the protection of crops and other natural resources against pathogens and pests.

\section{Conclusions}

The present data identifies $\beta$-CA enzymes that are expressed in a number of protozoans and metazoans. Metazoan and protozoan $\beta$-CAs represent promising diagnostic and therapeutic targets for parasitic infections, because this CA family is absent from mammalian proteomes. Many of these enzymes are predicted to be present in mitochondria where they might contribute to cell metabolism by providing bicarbonate for biosynthetic reactions and regulating intra-mitochondrial $\mathrm{pH}$.

\section{Additonal file}

Additional file 1: Figure S1. Multiple sequence alignment of all 75 $\beta$-CAs in metazoan and protozoan species with $\beta$-CA of Pelosinus fermentans (a bacterial out group). $\beta$-CAs contain two highly conserved active site motifs, $\mathrm{CxDxR}$ as well as $\mathrm{HxxC}(\mathrm{C}=\mathrm{Cysteine}, \mathrm{D}=\mathrm{Aspartic}$ acid, $\mathrm{R}=$ Arginine, $\mathrm{H}=$ Histidine, $\mathrm{C}=$ Cysteine) which are indicated by arrows. Alignment was visualized in Jalview [53].

\section{Competing interests}

The authors declare that they have no competing interests.

\section{Authors' contributions}

RZE, HB, MEET, CO carried out the bioinformatics searches on metazoan and protozoan species. RZE and HB participated in the sequence alignment and made the phylogenetic analysis. RZE performed the mitochondrial targeting peptide prediction. All authors participated in the design of the study. RZE and $\mathrm{HB}$ drafted the first version of the manuscript. All authors read and approved the final manuscript.

\section{Acknowledgement}

To perform these studies RZE received a scholarship support from the Ministry of Science, Research and Technology, and National Institute of Genetic Engineering and Biotechnology of Islamic Republic of Iran. This study was also funded by Finnish Cultural Foundation (HB), Academy of Finland (SP), Sigrid Juselius Foundation (SP), Jane and Aatos Erkko Foundation (SP), Tampere Tuberculosis Foundation (SP), and Competitive Research Funding of the Tampere University Hospital (SP; 9 N054).

\section{Author details}

'School of Medicine, University of Tampere, Medisiinarinkatu 3, 33520 Tampere, Finland. ${ }^{2}$ Institute of Biomedical Technology and BioMediTech, University of Tampere, 33520 Tampere, Finland. ${ }^{3}$ Department of Information Technology, University of Turku, 20520 Turku, Finland. ${ }^{4}$ Fimlab Ltd and Tampere University Hospital, Biokatu 4, 33520 Tampere, Finland.

Received: 9 October 2013 Accepted: 10 January 2014

Published: 21 January 2014

\section{References}

1. Elleuche S, Poggeler S: Carbonic anhydrases in fungi. Microbiology 2010, 156(Pt 1):23-29.

2. Huang S, Hainzl T, Grundstrom C, Forsman C, Samuelsson G, Sauer-Eriksson AE: Structural studies of beta-carbonic anhydrase from the green alga Coccomyxa: inhibitor complexes with anions and acetazolamide. PLoS One 2011, 6(12):e28458.

3. Supuran CT: Carbonic anhydrases: novel therapeutic applications for inhibitors and activators. Nat Rev Drug Discov 2008, 7(2):168-181.

4. Syrjanen L, Tolvanen M, Hilvo M, Olatubosun A, Innocenti A, Scozzafava A, Leppiniemi J, Niederhauser B, Hytonen VP, Gorr TA, et al: Characterization of the first beta-class carbonic anhydrase from an arthropod (Drosophila melanogaster) and phylogenetic analysis of beta-class carbonic anhydrases in invertebrates. BMC Biochem 2010, 11:28.

5. Tripp BC, Smith K, Ferry JG: Carbonic anhydrase: new insights for an ancient enzyme. J Biol Chem 2001, 276(52):48615-48618.

6. Elleuche S, Poggeler S: Evolution of carbonic anhydrases in fungi. Curr Genet 2009, 55(2):211-222.

7. Esbaugh AJ, Tufts BL: The structure and function of carbonic anhydrase isozymes in the respiratory system of vertebrates. Respir Physiol Neurobiol 2006, 154(1-2):185-198.

8. Lane TW, Saito MA, George GN, Pickering IJ, Prince RC, Morel FM: Biochemistry: a cadmium enzyme from a marine diatom. Nature 2005 435(7038):42.

9. $X u$ Y, Feng $L$, Jeffrey PD, Shi Y, Morel FM: Structure and metal exchange in the cadmium carbonic anhydrase of marine diatoms. Nature 2008, 452(7183):56-61.

10. Ferry JG: The gamma class of carbonic anhydrases. Biochim Biophys Acta 2010, 1804(2):374-381.

11. Alterio V, Vitale RM, Monti SM, Pedone C, Scozzafava A, Cecchi A, De Simone G, Supuran CT: Carbonic anhydrase inhibitors: X-ray and molecular modeling study for the interaction of a fluorescent antitumor sulfonamide with isozyme II and IX. J Am Chem Soc 2006, 128(25):8329-8335.

12. Nishimori I, Minakuchi T, Onishi S, Vullo D, Scozzafava A, Supuran CT: Carbonic anhydrase inhibitors. DNA cloning, characterization, and inhibition studies of the human secretory isoform $\mathrm{Vl}$, a new target for sulfonamide and sulfamate inhibitors. J Med Chem 2007, 50(2):381-388.

13. Vullo D, Franchi M, Gallori E, Antel J, Scozzafava A, Supuran CT: Carbonic anhydrase inhibitors. Inhibition of mitochondrial isozyme $V$ with aromatic and heterocyclic sulfonamides. J Med Chem 2004, 47(5):1272-1279.

14. Vullo D, Innocenti A, Nishimori I, Pastorek J, Scozzafava A, Pastorekova S, Supuran CT: Carbonic anhydrase inhibitors. Inhibition of the transmembrane isozyme XII with sulfonamides-a new target for the design of antitumor and antiglaucoma drugs? Bioorg Med Chem Lett 2005, 15(4):963-969.

15. Neish AC: Studies on chloroplasts: Their chemical composition and the distribution of certain metabolites between the chloroplasts and the remainder of the leaf. Biochem J 1939, 33(3):300-308.

16. Burnell JN, Gibbs MJ, Mason JG: Spinach chloroplastic carbonic anhydrase: nucleotide sequence analysis of cDNA. Plant Physiol 1990, 92(1):37-40.

17. Rowlett RS: Structure and catalytic mechanism of the beta-carbonic anhydrases. Biochim Biophys Acta 2010, 1804(2):362-373.

18. Fett JP, Coleman JR: Characterization and expression of two cDNAs encoding carbonic anhydrase in Arabidopsis thaliana. Plant Physiol 1994, 105(2):707-713.

19. Majeau N, Coleman JR: Nucleotide sequence of a complementary DNA encoding tobacco chloroplastic carbonic anhydrase. Plant Physiol 1992, 100(2):1077-1078.

20. Cronk JD, Endrizzi JA, Cronk MR, O'Neill JW, Zhang KY: Crystal structure of E. coli beta-carbonic anhydrase, an enzyme with an unusual pH-dependent activity. Protein Sci 2001, 10(5):911-922. 
21. Guilloton MB, Korte JJ, Lamblin AF, Fuchs JA, Anderson PM: Carbonic anhydrase in Escherichia coli. A product of the cyn operon. $J$ Biol Chem 1992, 267(6):3731-3734.

22. Smith KS, Ferry JG: A plant-type (beta-class) carbonic anhydrase in the thermophilic methanoarchaeon Methanobacterium thermoautotrophicum. J Bacteriol 1999, 181(20):6247-6253.

23. Rowlett RS, Tu C, Lee J, Herman AG, Chapnick DA, Shah SH, Gareiss PC: Allosteric site variants of Haemophilus influenzae beta-carbonic anhydrase. Biochemistry 2009, 48(26):6146-6156.

24. Supuran CT: Bacterial carbonic anhydrases as drug targets: toward novel antibiotics? Front Pharmacol 2011, 2:34.

25. Joseph P, Turtaut F, Ouahrani-Bettache S, Montero JL, Nishimori I, Minakuchi T, Vullo D, Scozzafava A, Kohler S, Winum JY, et al: Cloning, characterization, and inhibition studies of a beta-carbonic anhydrase from Brucella suis. J Med Chem 2010, 53(5):2277-2285.

26. Burghout $P$, Vullo D, Scozzafava A, Hermans PW, Supuran CT: Inhibition of the beta-carbonic anhydrase from Streptococcus pneumoniae by inorganic anions and small molecules: Toward innovative drug design of antiinfectives? Bioorg Med Chem 2011, 19(1):243-248.

27. Vullo D, Nishimori I, Minakuchi T, Scozzafava A, Supuran CT: Inhibition studies with anions and small molecules of two novel beta-carbonic anhydrases from the bacterial pathogen Salmonella enterica serovar Typhimurium. Bioorg Med Chem Lett 2011, 21(12):3591-3595.

28. Abuaita $\mathrm{BH}$, Withey $\mathrm{JH}$ : Bicarbonate Induces Vibrio cholerae virulence gene expression by enhancing ToxT activity. Infect Immun 2009 77(9):4111-4120.

29. Kovacikova G, Lin W, Skorupski K: The LysR-type virulence activator AphB regulates the expression of genes in Vibrio cholerae in response to low pH and anaerobiosis. J Bacterio/ 2010, 192(16):4181-4191.

30. Klengel T, Liang WJ, Chaloupka J, Ruoff C, Schroppel K, Naglik JR, Eckert SE, Mogensen EG, Haynes K, Tuite MF, et al: Fungal adenylyl cyclase integrates CO2 sensing with CAMP signaling and virulence. Curr Biol 2005, 15(22):2021-2026.

31. Innocenti A, Leewattanapasuk W, Muhlschlegel FA, Mastrolorenzo A Supuran CT: Carbonic anhydrase inhibitors. Inhibition of the beta-class enzyme from the pathogenic yeast Candida glabrata with anions. Bioorg Med Chem Lett 2009, 19(16):4802-4805.

32. Bahn YS, Cox GM, Perfect JR, Heitman J: Carbonic anhydrase and CO2 sensing during Cryptococcus neoformans growth, differentiation, and virulence. Curr Biol 2005, 15(22):2013-2020.

33. Elleuche $S$, Poggeler $S$ : A cyanase is transcriptionally regulated by arginine and involved in cyanate decomposition in Sordaria macrospora. Fungal Genet Biol 2008, 45(11):1458-1469.

34. Amoroso G, Morell-Avrahov L, Muller D, Klug K, Sultemeyer D: The gene NCE103 (YNL036w) from Saccharomyces cerevisiae encodes a functional carbonic anhydrase and its transcription is regulated by the concentration of inorganic carbon in the medium. Mol Microbiol 2005, 56(2):549-558.

35. Cleves AE, Cooper DN, Barondes SH, Kelly RB: A new pathway for protein export in Saccharomyces cerevisiae. J Cell Biol 1996, 133(5):1017-1026.

36. Gotz R, Gnann A, Zimmermann FK: Deletion of the carbonic anhydraselike gene NCE103 of the yeast Saccharomyces cerevisiae causes an oxygen-sensitive growth defect. Yeast 1999, 15(10A):855-864.

37. So AK, Espie GS: Cloning, characterization and expression of carbonic anhydrase from the cyanobacterium Synechocystis PCC6803. Plant Mol Biol 1998, 37(2):205-215.

38. Sawaya MR, Cannon GC, Heinhorst S, Tanaka S, Williams EB, Yeates TO, Kerfeld CA: The structure of beta-carbonic anhydrase from the carboxysomal shell reveals a distinct subclass with one active site for the price of two. J Biol Chem 2006, 281(11):7546-7555.

39. Eriksson M, Karlsson J, Ramazanov Z, Gardestrom P, Samuelsson G: Discovery of an algal mitochondrial carbonic anhydrase: molecular cloning and characterization of a low-CO2-induced polypeptide in Chlamydomonas reinhardtii. Proc Natl Acad Sci U S A 1996, 93(21):12031-12034

40. Mitsuhashi S, Mizushima T, Yamashita E, Yamamoto M, Kumasaka T, Moriyama H, Ueki T, Miyachi S, Tsukihara T: X-ray structure of beta-carbonic anhydrase from the red alga, Porphyridium purpureum, reveals a novel catalytic site for $\mathrm{CO}(2)$ hydration. J Biol Chem 2000, 275(8):5521-5526.

41. Fasseas MK, Tsikou D, Flemetakis E, Katinakis P: Molecular and biochemical analysis of the beta class carbonic anhydrases in Caenorhabditis elegans. Mol Biol Rep 2010, 37(6):2941-2950
42. Guilloton MB, Lamblin AF, Kozliak El, Gerami-Nejad M, Tu C, Silverman D, Anderson PM, Fuchs JA: A physiological role for cyanate-induced carbonic anhydrase in Escherichia coli. J Bacteriol 1993, 175(5):1443-1451.

43. Nishimori I, Onishi S, Takeuchi H, Supuran CT: The alpha and beta classes carbonic anhydrases from Helicobacter pylori as novel drug targets. Curr Pharm Des 2008, 14(7):622-630.

44. Mitsuhashi S, Ohnishi J, Hayashi M, Ikeda M: A gene homologous to beta-type carbonic anhydrase is essential for the growth of Corynebacterium glutamicum under atmospheric conditions. Appl Microbiol Biotechnol 2004, 63(5):592-601

45. Fukuzawa H, Suzuki E, Komukai Y, Miyachi S: A gene homologous to chloroplast carbonic anhydrase (icfA) is essential to photosynthetic carbon dioxide fixation by Synechococcus PCC7942. Proc Natl Acad SC U S A 1992, 89(10):4437-4441

46. Merlin C, Masters M, McAteer S, Coulson A: Why is carbonic anhydrase essential to Escherichia coli? J Bacteriol 2003, 185(21):6415-6424

47. Majeau N, Coleman JR: Effect of $\mathrm{CO} 2$ Concentration on Carbonic Anhydrase and Ribulose-1,5-Bisphosphate Carboxylase/Oxygenase Expression in Pea. Plant Physiol 1996, 112(2):569-574.

48. Tetu SG, Tanz SK, Vella N, Burnell JN, Ludwig M: The Flaveria bidentis beta-carbonic anhydrase gene family encodes cytosolic and chloroplastic isoforms demonstrating distinct organ-specific expression patterns. Plant Physiol 2007, 144(3):1316-1327.

49. Ludwig M: The molecular evolution of beta-carbonic anhydrase in Flaveria. J Exp Bot 2011, 62(9):3071-3081.

50. Zabaleta E, Martin MV, Braun HP: A basal carbon concentrating mechanism in plants? Plant Sci: Int J Exp Plant Biol 2012, 187:97-104.

51. Kimber MS, Pai EF: The active site architecture of Pisum sativum beta-carbonic anhydrase is a mirror image of that of alpha-carbonic anhydrases. EMBO J 2000, 19(7):1407-1418.

52. Mitsuhashi S, Mizushima T, Yamashita E, Miyachi S, Tsukihara T: Crystallization and preliminary X-ray diffraction studies of a beta-carbonic anhydrase from the red alga Porphyridium purpureum. Acta Crystallogr D Biol Crystallogr 2000, 56(Pt 2):210-211.

53. Waterhouse AM, Procter JB, Martin DM, Clamp M, Barton GJ: Jalview Version 2-a multiple sequence alignment editor and analysis workbench. Bioinformatics 2009, 25(9):1189-1191.

54. Sievers F, Wilm A, Dineen D, Gibson TJ, Karplus K, Li W, Lopez R, McWilliam H, Remmert M, Soding J, et al: Fast, scalable generation of high-quality protein multiple sequence alignments using Clustal Omega. Mol Syst Bio/ 2011, 7:539

55. Suyama M, Torrents D, Bork P: PAL2NAL: robust conversion of protein sequence alignments into the corresponding codon alignments. Nucleic Acids Res 2006, 34:W609-W612. eb Server issue.

56. Ronquist F, Teslenko M, Van der Mark P, Ayres DL, Darling A, Hohna S, Larget B, Liu L, Suchard MA, Huelsenbeck JP: MrBayes 3.2: efficient Bayesian phylogenetic inference and model choice across a large model space. Syst Biol 2012, 61(3):539-542

57. Brown SD, Podar M, Klingeman DM, Johnson CM, Yang ZK, Utturkar SM, Land ML, Mosher JJ, Hurt RA Jr, Phelps TJ, et al: Draft genome sequences for two metal-reducing Pelosinus fermentans strains isolated from a $\mathrm{Cr}$ (VI)-contaminated site and for type strain R7. J Bacterio/ 2012, 194(18):5147-5148.

58. Guindon S, Dufayard JF, Lefort V, Anisimova M, Hordijk W, Gascuel O: New algorithms and methods to estimate maximum-likelihood phylogenies: assessing the performance of PhyML 3.0. Systematic biology 2010, 59(3):307-321.

59. Emanuelsson $\mathrm{O}$, Nielsen $\mathrm{H}$, Brunak $\mathrm{S}$, von Heijne G: Predicting subcellular localization of proteins based on their $\mathrm{N}$-terminal amino acid sequence. J Mol Biol 2000, 300(4):1005-1016.

60. Woese CR: Interpreting the universal phylogenetic tree. Proc Natl Acad Sci U S A 2000, 97(15):8392-8396.

61. Fabre N, Reiter IM, Becuwe-Linka N, Genty B, Rumeau D: Characterization and expression analysis of genes encoding alpha and beta carbonic anhydrases in Arabidopsis. Plant Cell Environ 2007, 30(5):617-629.

62. Mitra M, Lato SM, Ynalvez RA, Xiao Y, Moroney JV: Identification of a new chloroplast carbonic anhydrase in Chlamydomonas reinhardtii. Plant Physiol 2004, 135(1):173-182.

63. Bahn YS, Muhlschlegel FA: CO2 sensing in fungi and beyond. Curr Opin Microbiol 2006, 9(6):572-578. 
64. Shah GN, Rubbelke TS, Hendin J, Nguyen H, Waheed A, Shoemaker JD, Sly WS: Targeted mutagenesis of mitochondrial carbonic anhydrases VA and VB implicates both enzymes in ammonia detoxification and glucose metabolism. Proc Natl Acad Sci U S A 2013, 110(18):7423-7428.

65. Fleige T, Pfaff N, Gross $U$, Bohne W: Localisation of gluconeogenesis and tricarboxylic acid (TCA)-cycle enzymes and first functional analysis of the TCA cycle in Toxoplasma gondii. Int J Parasit 2008, 38(10):1121-1132.

66. Hazen SA, Waheed A, Sly WS, LaNoue KF, Lynch CJ: Differentiation-dependent expression of CA $V$ and the role of carbonic anhydrase isozymes in pyruvate carboxylation in adipocytes. FASEB J 1996, 10(4):481-490.

67. Ramakrishnan S, Serricchio M, Striepen B, Butikofer P: Lipid synthesis in protozoan parasites: A comparison between kinetoplastids and apicomplexans. Prog Lipid Res 2013, 52(4):488-512.

68. Murakami H, Sly WS: Purification and characterization of human salivary carbonic anhydrase. J Biol Chem 1987, 262(3):1382-1388.

69. Juhn J, Naeem-Ullah U, Maciel Guedes BA, Majid A, Coleman J, Paolucci Pimenta PF, Akram W, James AA, Marinotti O: Spatial mapping of gene expression in the salivary glands of the dengue vector mosquito, Aedes aegypti. Parasit Vectors 2011, 4:1.

70. Moreira-Ferro CK, Marinotti O, Bijovsky AT: Morphological and biochemical analyses of the salivary glands of the malaria vector, Anopheles darlingi. Tissue Cell 1999, 31(3):264-273.

71. Maresca A, Scozzafava A, Kohler S, Winum JY, Supuran CT: Inhibition of beta-carbonic anhydrases from the bacterial pathogen Brucella suis with inorganic anions. J Inorg Biochem 2012, 110:36-39.

72. Isik S, Guler OO, Kockar F, Aydin M, Arslan O, Supuran CT: Saccharomyces cerevisiae beta-carbonic anhydrase: inhibition and activation studies. Curr Pharm Des 2010, 16(29):3327-3336.

73. Isik S, Kockar F, Aydin M, Arslan O, Guler OO, Innocenti A, Scozzafava A, Supuran CT: Carbonic anhydrase inhibitors: inhibition of the beta-class enzyme from the yeast Saccharomyces cerevisiae with sulfonamides and sulfamates. Bioorg Med Chem 2009, 17(3):1158-1163.

74. Monti SM, Maresca A, Viparelli F, Carta F, De Simone G, Muhlschlegel FA, Scozzafava A, Supuran CT: Dithiocarbamates are strong inhibitors of the beta-class fungal carbonic anhydrases from Cryptococcus neoformans, Candida albicans and Candida glabrata. Bioorg Med Chem Lett 2012, 22(2):859-862.

75. Guzel O, Maresca A, Hall RA, Scozzafava A, Mastrolorenzo A, Muhlschlegel FA, Supuran $C$ : Carbonic anhydrase inhibitors. The beta-carbonic anhydrases from the fungal pathogens Cryptococcus neoformans and Candida albicans are strongly inhibited by substituted-phenyl-1H-indole-5-sulfonamides. Bioorg Med Chem Lett 2010, 20(8):2508-2511.

doi:10.1186/1756-3305-7-38

Cite this article as: Zolfaghari Emameh et al:: Bioinformatic analysis of beta carbonic anhydrase sequences from protozoans and metazoans. Parasites \& Vectors 2014 7:38.

\section{Submit your next manuscript to BioMed Central and take full advantage of:}

- Convenient online submission

- Thorough peer review

- No space constraints or color figure charges

- Immediate publication on acceptance

- Inclusion in PubMed, CAS, Scopus and Google Scholar

- Research which is freely available for redistribution

Submit your manuscript at www.biomedcentral.com/submit
C Biomed Central 